\title{
APROXIMACIÓN AL ACOSO LABORAL DESDE LA LEGISLACIÓN COMPARADA*
}

\section{AN APPROACH TO HARASSMENT IN THE WORKPLACE FROM A COMPARATIVE PERSPECTIVE}

\section{María Ascensión MORALEs RAMÍREZ ${ }^{* *}$}

RESUMEN: Las conductas abusivas que se dan en el ámbito de las relaciones en el trabajo han cobrado importancia en estudios de diversas disciplinas. Sin embargo, al ser un fenómeno cuya problematización es de carácter laboral y que cada día es más frecuente, sus causas y consecuencias han sido consideradas por las instancias jurídicas internacionales y nacionales para su tratamiento legal. Por ello, resulta interesante identificar el papel jugado por el derecho respecto de esta temática, tanto en el hecho de su regulación como en el de su combate. En forma específica, se necesita revisar el desarrollo jurídico ocurrido en las últimas décadas, y determinar tanto el enfoque como el grado alcanzado a la luz de los documentos de la Organización Internacional del Trabajo, la Unión Europea y América Latina.

Palabras clave: Acoso laboral, legislación sobre el acoso laboral, tratamiento jurídico del acoso laboral.
ABSTRACT: The abusive behavior that takes place in labor relations has gained the attention of researchers in several fields. However, since it is a phenomenon of work-related problematization and is becoming more frequent in the working world, international and national legal agencies have been analyzing the legal treatment of the causes and consequences of this. Therefore, it is fitting to identify the role of the law in such situations from the perspective of regulating it, as well as fighting against it. More particularly, the legal developments of recent decades need to be examined while its focus and scope should be established in the light of documents originated from the International Labour Organization, European Union and Latin America.

Keyzerds: Workplace harassment, legislation on harassment, legal treatment of workplace harassment.

* Artículo recibido el 24 de septiembre de 2015 y aceptado para su publicación el 21 de abril de 2016.

** Profesora de Derecho del trabajo y la seguridad social en la Facultad de Derecho de la UNAM.

Boletín Mexicano de Derecho Comparado nueva serie, año XLIX, núm. 147, septiembre-diciembre de 2016, pp. 71-98

D. R. (C) 2016. UNAM, Instituto de Investigaciones Jurídicas. 
SUMARIO: I. Introducción. II. Conceptualización. III. Organización Internacional del Trabajo. IV. Unión Europea. V. América Latina. VI. Conclusiones. VII. Bibliografia.

\section{INTRODUCGIÓN}

Conductas como la violencia, la intimidación, y otros comportamientos abusivos en el trabajo, en cierta medida, siempre han existido. Estos actos fueron objeto de estudio, ${ }^{1}$ en forma particular, en las décadas de los ochenta y noventa, entre otros, por Heinz Leymann y Marie-France Hirigoyen, ${ }^{2}$ quienes investigaron sobre determinadas conductas en el ámbito laboral y sus efectos en los trabajadores. ${ }^{3}$

Sin embargo, con el cambio en la organización y en las formas del trabajo, esta compleja situación, en la práctica, ha tendido a crecer en el ámbito de las relaciones laborales privadas y públicas. Por ello, en las últimas décadas el fenómeno ha cobrado relevancia y visibilidad por varios factores: a) las diversas investigaciones al respecto; b) el desarrollo de los derechos fundamentales en el trabajo; c) las leyes aprobadas recientemente en varios países con el objeto de prevenir y evitar el fenómeno, y d) la nueva normativa de los emergentes riesgos psicosociales (porque se considera un riesgo para la salud, ya que produce enfermedades).

Para los fines de este estudio, a lo que denominaremos "acoso laboral", actualmente, se le reconocen varios efectos, entre otros: vulnera derechos fundamentales de la persona; genera nuevas enfermedades que se añaden a los riesgos tradicionales propios de la sociedad industrial; afecta a las empresas por la reducción en la productividad y el incremento en los costos (por el ausentismo, mayor rotación de personal, etcétera), y daña a la sociedad en general, porque - como lo reconoce la Organización de las Naciones Unidas - es un problema de salud pública.

1 En la década de los sesenta, el etólogo Konrad Lorenz estudió el comportamiento de ciertas aves que a través de la conducta realizada en grupo conseguían ahuyentar de su territorio a otra ave de mayores dimensiones. Cfr. Lorenz, Konrad, Sobre la agresión: el pretendido mal, México, Siglo Veintiuno, 1985.

2 Leymann, Heinz, Mobbing. La persécution au travail, Seúl-París, 1996; Hirigoyen, Marie-France, El acoso moral. El maltrato psicológico en la vida cotidiana, Madrid, Paidós, 1999.

3 El auge de las investigaciones se dio entre 1980 y 2000, específicamente en los países escandinavos (Suecia, Noruega y Finlandia). 
En este sentido, el tema presenta diversos ángulos desde los que se puede abordar. Las causas, las características, las repercusiones y las magnitudes del hecho expuestas por las investigaciones psicosociales han sido ya consideradas en diferentes instancias jurídicas internacionales y nacionales.

Puede adelantarse que las normas de prevención y combate del acoso laboral aparecen reguladas en:

a) Legislaciones ad hoc, es decir, leyes específicamente dirigidas a prevenir y erradicar el acoso laboral, las cuales han aparecido en los últimos años en algunos países. También la ley ad hoc contiene normas de reforma de varias legislaciones no específicas y que, por tanto, sus disposiciones están destinadas a convertirse en artículos de códigos diversos.

b) Legislaciones de carácter general que regulan cualquier circunstancia de la vida social, las cuales incluyen normas que podrían ser aplicadas al acoso laboral, a saber: constitucionales y legales.

En razón de lo anterior, el objetivo del presente estudio es exponer el desarrollo del tratamiento relativo al acoso laboral en los ordenamientos jurídicos tanto en el plano internacional como en el nacional, con base en las leyes y las prácticas adoptadas por los países. No se pretende hacer un análisis exhaustivo, pormenorizado o prescriptivo del asunto, sino reseñar las iniciativas adoptadas por un importante grupo de países que en forma paralela al debate sobre el acoso laboral han avanzado en el tema, teniendo puntos de partida, visiones e instrumentos diferentes. En resumen, se busca destacar algunos elementos que permitan identificar el papel jugado por el derecho al respecto.

Para ello, primero se revisa la problemática derivada de los conceptos, definiciones y características respecto del tema, que permita en forma sintética conceptualizar esta compleja situación, ${ }^{4}$ y segundo, justificar la adopción del concepto "acoso laboral" en el presente estudio e intentar una aproximación teórica en el ámbito jurídico. Posteriormente, se analiza el hecho a la luz del entorno normativo en la Organización Internacional del Trabajo (OIT), la Unión Europea y América Latina. Finalmente, se formulan algunas conclusiones.

4 Será en forma sintética, porque los diversos puntos han sido ampliamente abordados por la extensa literatura proveniente de las diversas disciplinas. 
Esta revista forma parte del acervo de la Biblioteca Jurídica Virtual del Instituto de Investigaciones Jurídicas de la UNAM

\section{GONGEPTUALIZAGiÓN}

\section{Terminología}

Los estudios sobre el tema surgieron, principalmente, en disciplinas como la psicología, psiquiatría y sociología, tal y como da cuenta la extensa literatura; sin embargo, en ella se reconoce la existencia de una estrecha relación entre éste y determinadas formas de organización del trabajo, ${ }^{5}$ las cuales dan lugar a situaciones, causas y problemas que requieren soluciones distintas. En razón de lo anterior, el fenómeno admite una pluralidad de términos en distintos campos disciplinarios para describir formas particulares de degeneración de relaciones particulares en el ámbito laboral.

En la doctrina e investigaciones sobre el tema suelen encontrarse, entre otros, los siguientes términos: mobbing, ${ }^{6}$ psicoterror, terror psicológico, asedio moral, violencia psicológica en el trabajo, acoso laboral, acoso moral, hostigamiento en el trabajo, violencia laboral, violencia en el lugar de trabajo, etcétera.

Como puede apreciarse, la denominación del hecho es un tema de discusión. Al respecto, Elena y Peña ofrece una clasificación de las diferentes acepciones en cuatro grupos: 1) términos relacionados pero poco equivalentes (opresión, subrogación, comportamiento abusivo, etcétera); 2) términos referidos a un concepto más amplio (violencia, agresión o comportamiento antisocial en el trabajo); 3) expresiones parciales (bossing, tiranía mezquina), y 4) términos equivalentes. ${ }^{7}$

\section{Definiciones}

Igualmente, abundan las definiciones para determinar el fenómeno, en función del criterio, matices, frecuencia y conductas empleadas por cada

5 Hirigoyen, Marie-France, El acoso moral en el trabajo: distinguir lo verdadero de lo falso, Barcelona, Paidós, 2011 ; Piñuel y Zabala, Iñaki, Mobbing: cómo sobrevivir al acoso psicológico en el trabajo, Bilbao, Sal Terrae, 2001; Plena Saint, Florencia et al., Cuando el trabajo nos castiga. Debates sobre el mobbing en México, México, ONM-Sedisem-UAM Azcapotzalco, 2007.

6 La palabra mobbing deriva del término inglés mob, que significa - entre otras acepciones - acosar, asediar o atacar en grupo, y del latín mobile vulgus, que se traduce como "multitud, turba, muchedumbre".

7 López Cabarcos y Vázquez Rodríguez proporcionan en su estudio dieciocho términos y definiciones a nivel de la doctrina internacional. Cfr. López Cabarcos, M. Ángeles y Vázquez Rodríguez, Paula, El mobbing en las organizaciones. La ausencia de un concepto legal y único, 2007. 
autor, por lo que no existe una definición aceptada universalmente que recoja en forma completa todos sus elementos distintivos, pues al tratarse de un hecho multifacético, éste tropieza con dificultades conceptuales, normativas, inconvenientes y problemas de distinta intensidad en los contextos internacionales y nacionales. Además, el tema abarca realidades muy diversas; por ello, el primer paso es reconocer la heterogeneidad de situaciones, perfiles y comportamientos. No obstante, sirven de ejemplo las definiciones de los artífices de los principales estudios psicosociales sobre el tema:

Heinz Leymann lo define como

...Aquel fenómeno en que una persona o grupo de personas ejerce una violencia psicológica extrema, de forma sistemática y recurrente - al menos una vez por semana - y durante un tiempo prolongado — más de seis meses - sobre otra persona en el lugar de trabajo, con la finalidad de destruir las redes de comunicación de la víctima o víctimas, destruir su reputación, perturbar el ejercicio de sus labores y lograr finalmente que esa persona o personas acaben abandonando el lugar de trabajo. ${ }^{8}$

Por otro lado, Marie-France Hirigoyen establece que son "Conductas reiteradas, con un objetivo determinado (dominar y controlar al otro), que violentan la dignidad del trabajador o su integridad psíquica y ponen en peligro su puesto de trabajo o degrada en el ambiente laboral". ${ }^{9}$

\section{Características}

Como se había señalado, existe literatura e investigaciones extensas que conceptualizan de forma amplia la temática, razón por la cual a continuación se exponen sintéticamente sus características, porque este rubro por sí solo ameritaría un estudio propio, situación que excede la finalidad del presente trabajo.

El acoso laboral con sus comportamientos recurrentes y sistemáticos pretende la afectación de la víctima por un individuo o grupos de individuos, cuya finalidad última puede atender a diferentes causas: por el lado

8 Leymann usó la expresión mobbing. Cfr. Leymann, Heinz, Mobbing..., cit.

9 Hirigoyen emplea el término "acoso moral". Cfr. Hirigoyen, Marie-France, El acoso moral en el trabajo..., cit. 
de la empresa, podría ser el deshacerse de un trabajador, ya sea por la modificación estructural de la empresa o simplemente para evitar el ejercicio de ciertos derechos laborales, entre ellos la indemnización. ${ }^{10}$ Por otra parte, pueden ser resultado de envidia personal y/o profesional, pero en ambos casos se degradan las condiciones de trabajo. A modo de ejemplo se señalan como elementos de su caracterización a los siguientes:

a) Sujetos. El fenómeno requiere de dos actores: el acosador y la víctima.

b) Conductas. La extensa literatura sobre el tema distingue una serie de comportamientos típicos, que pueden considerarse como constitutivos del acoso laboral; de manera general, tenemos, entre otros, a los siguientes: ${ }^{11}$

- Atentados en las condiciones de trabajo: cambiar funciones, retirar trabajos realizados en forma habitual, negar herramientas o información para el desarrollo de sus funciones, etcétera.

- Atentados a la dignidad personal: ridiculizar alguna característica o correr rumores sobre el trabajador afectado, etcétera.

- Aislamiento: no dirigir la palabra al afectado, destinarlo a oficinas aisladas del resto del equipo de trabajo, etcétera.

- Actos de violencia verbal o psicológica: uso de violencia menor en contra, insultos, etcétera.

c) Modalidades. En atención a la posición que ocupan el sujeto activo y el pasivo dentro de la empresa, el acoso laboral puede clasificarse en:

- Acoso vertical descendente. Es el comportamiento en que el agresor es el superior jerárquico del trabajador afectado.

- Ascendente. Es la forma en que una persona de rango jerárquico superior en la organización es objeto de agresión de uno o varios subordinados (puede presentarse cuando es de nuevo ingreso en la empresa y los trabajadores no aceptan su forma de trabajo, o bien se trata de alguien que fue promovido y sus antiguos compañeros no aceptan su nueva jerarquía).

10 Los estudios en la materia suelen señalar una estrecha relación entre el acoso laboral y las determinadas formas de organización del trabajo, como en aquéllas en donde se favorece los estilos de dirección autoritarios, o bien existe una fuerte limitación a la protección del trabajador.

11 Se han llegado a describir hasta 45 comportamientos distintos. Cfr. Leymann, Heinz, Inventory Psychological Terrorization, 1990. 
- Horizontal. Se manifiesta entre compañeros del mismo nivel (puede tratarse de envidia, celos, entre otros).

d) Fases. Suele tratarse de situaciones sistemáticas y continuas en el tiempo, porque el acoso laboral es un proceso. Entre algunas de sus fases se distinguen: conflicto, estigmatización, intervención de la empresa, marginación o exclusión de la vida laboral. ${ }^{12}$

e) Efectos. El acoso laboral puede generar efectos evidentes a nivel psicológico, físico y social de la víctima (depresión, ansiedad, ataques de pánico, irritabilidad, disminución de la autoestima, entre otros). Independientemente de la duración, la intensidad y de las características del acoso laboral, además de producir distintos grados de trastornos psicosomáticos, también el evento atenta contra la dignidad y los derechos fundamentales del individuo.

f) Excepciones. No constituyen comportamientos de acoso laboral las cuestiones de orden disciplinario; el cumplimiento de obligaciones; los conflictos temporales al interior de la empresa entre sus miembros, cuando el objetivo es mejorar el trabajo y el rendimiento, entre otras.

\section{Aproximación teórica al ámbito jurídico}

La pluralidad de conceptos, así como de definiciones existentes en las diversas disciplinas, obliga a adoptar algunas para su aproximación al campo jurídico, en atención a su problematización como fenómeno laboral.

Término. En el presente estudio se utilizará "acoso laboral" como concepto normativo, porque los comportamientos que se aducen al hecho surgen precisamente en el ámbito de la relaciones en el trabajo, siendo consciente de que múltiples conceptos jurídicos tardan tiempo en consensarse y consolidarse.

Definiciones. Se emplearán las elaboradas por la OIT y la Comisión Europea, porque dichas instancias internacionales, en sus respectivas definiciones normativas con relación a la temática, en alguna medida toman en cuenta las causas, las características, las magnitudes y las repercusiones señaladas en las investigaciones psicosociales: ${ }^{13}$

12 Según el tipo de autor, las fases del acoso laboral pueden ser desde cuatro o más de siete.

13 Ambos organismos internacionales emplean el concepto de violencia en el trabajo, aunque en el documento de la OIT de 2011, Promover la igualdad entre mujeres y hombres en el 
a) La OIT define el acoso laboral como la "acción verbal o psicológica de índole sistemática, repetida o persistente por la que, en el lugar de trabajo en conexión con el trabajo, una persona o un grupo de personas hiere a una víctima, la humilla, ofende o amedrenta". ${ }^{14}$ Con base en esta definición, la Organización Internacional señala algunos de sus efectos: "Provoca una alteración inmediata y a menudo duradera en las relaciones interpersonales, la organización del trabajo y el entorno laboral en su conjunto, con costos directos en el ámbito de la seguridad e indirectos que condicionan la eficiencia y la productividad". ${ }^{15}$

b) La Comisión Europea señala que el acoso laboral es un "comportamiento negativo entre compañeros o entre superiores e inferiores jerárquicos, a causa del cual el afectado es objeto de acoso y ataques sistemáticos durante mucho tiempo, de modo directo e indirecto, por parte de una o más personas, con el objetivo y/o el efecto de hacerle el vacío". ${ }^{16}$ Esta definición constituyó un paso previo de un proyecto de directiva comunitaria que orientara la prevención, la observación de los derechos de los trabajadores afectados, la vigilancia de la salud y el comienzo de una campaña de sensibilización.

A continuación se describirá el desarrollo jurídico ocurrido en las últimas décadas con respecto al tema.

\section{ORGANIZAGIÓN INTERNAGIONAL DEL TRABAJO}

Los instrumentos de la OIT constituyen una de las principales fuentes del marco normativo internacional para atender las problemáticas en el campo laboral; sin embargo, hasta el momento dicho organismo no cuenta con un instrumento jurídico específico que regule el acoso laboral. A pesar de ello, la OIT considera que algunos de sus instrumentos atienden este tema, y constituyen elementos importantes para prevenirlo y combatirlo, tales

trabajo: una cuestión de principios, dicho organismo usa el concepto de "acoso laboral". Disponible en: wrwe.ilo.org/sanjose/programas y proyecto/verificacionimplementaciónlibroblanco.

14 OIT, Violencia en el trabajo, Ginebra, 2000.

15 Idem.

16 La definición fue propuesta por el Grupo de Estudio "Violencia en el Trabajo" (con representantes de gobiernos, empleadores y sindicatos). Cfr. Gimeno, 2005. Cit. por López Cobarcos, M. Ángeles y Vázquez Rodríguez, Paula, op. cit., p. 9. 
como: a) el Convenio 155 sobre seguridad y salud de los trabajadores; b) el Convenio 111 sobre discriminación (empleo y ocupación) y la Recomendación 111 respectiva; c) las recomendaciones emitidas por dicho organismo en 2003, y d) la inclusión de los riesgos psicosociales en 2010 en la lista de enfermedades profesionales.

\section{Convenio 155}

De acuerdo a lo establecido en este Convenio, un medio ambiente laboral seguro y saludable facilita un estado de salud físico y mental óptimo; asimismo, contribuye a prevenir la violencia en el lugar de trabajo.

\section{Convenio y Recomendación 111}

Este instrumento sobre la discriminación (empleo y ocupación) se ubica entre los ocho convenios fundamentales de la Declaración de la OIT relativa a los principios y derechos fundamentales en el trabajo. El Convenio busca propiciar condiciones para contribuir al logro de la igualdad de oportunidades en el empleo y la ocupación. Igualmente, la OIT señala que con base en dicho Convenio, toda política o medida encaminada a combatir la violencia en el lugar de trabajo debería apuntar, asimismo, a promover el trabajo decente y el respeto mutuo, y a combatir la discriminación en el lugar de trabajo.

Por su parte, la Recomendación 111 exige una acción continuada con el fin de alcanzar progresivamente sus objetivos, y prevé una evaluación de los resultados obtenidos en la implementación de la política nacional sobre igualdad, con el propósito de revisar y ajustar las medidas, así como las estrategias existentes de manera continuada.

\section{Recomendaciones prácticas}

En 2003, la OIT realizó una serie de recomendaciones ${ }^{17}$ sobre la violencia en el lugar del trabajo en el sector de servicios. ${ }^{18}$ Si bien estas re-

17 OIT, Repertorio de recomendaciones prácticas sobre la violencia en el lugar de trabajo en el sector de los servicios y medidas para combatirla, Ginebra, Oficina Internacional del Trabajo, 2003.

18 Por su parte, en 2004 la Organización Mundial de la Salud impulsó la elaboración de guías y códigos de comportamientos éticos en las empresas. 
comendaciones no gozan de fuerza jurídica, pretenden ofrecer una guía a los Estados para promover la prevención de la salud y seguridad en el trabajo. Las medidas comprenden la identificación del fenómeno, la evaluación del riesgo, la prevención y control, la formación de trabajadores, la eliminación de impactos, la asistencia a la víctima y la supervisión. ${ }^{19}$

\section{Lista de enfermedades profesionales de la OIT}

El 25 de mayo de 2010 el Consejo de Administración de la OIT, en su reunión 307a., aprobó una nueva lista de enfermedades profesionales, la cual sustituyó a la que figuraba en el anexo de la Recomendación 194, adoptada en 2002. La nueva lista refleja el desarrollo, la identificación y el reconocimiento de enfermedades profesionales en el mundo actual; asimismo, indica en dónde aplicar la prevención y la protección. Adicionalmente, esta lista sirve de modelo para el establecimiento, el examen y la revisión de las listas nacionales.

El mérito de dicha lista es que incluye por primera vez los trastornos mentales y del comportamiento, es decir, las enfermedades psicosociales, en su numeral 2.4. Además, se comprenden puntos abiertos para permitir el reconocimiento del origen profesional de enfermedades que no figuran en la lista, siempre y cuando se haya establecido un vínculo entre la exposición a los factores de riesgo que resulte de la actividad laboral y las enfermedades contraídas por el trabajador. ${ }^{20}$ En este marco cobra cada vez mayor fuerza el reconocimiento del "acoso moral" como enfermedad psicosocial.

De acuerdo con los cuatro instrumentos descritos, puede apreciarse que la OIT adopta un enfoque previsor, basado principalmente en los sistemas de gestión de la seguridad y salud en el trabajo.

\section{UNIÓN EUROPEA}

La Unión Europea desde hace varias décadas también ha prestado atención al acoso laboral. Destacan por su importancia al menos tres documentos comunitarios, y dentro de las legislaciones nacionales se identifican cuatro

19 OIT, Repertorio de recomendaciones..., cit.

20 OIT, Lista de enfermedades profesionales de la OIT (revisada en 2010), Ginebra, 2010. 
Esta revista forma parte del acervo de la Biblioteca Jurídica Virtual del Instituto de Investigaciones Jurídicas de la UNAM

leyes específicas, así como su inclusión en otros tantos ordenamientos y figuras jurídicas diversas. ${ }^{21}$

\section{Documentos comunitarios}

\section{A. Resolución del Parlamento Europeo sobre el acoso moral en el lugar de trabajo, 2001/2339(INI)}

Esta Resolución fue emitida el 20 de septiembre de 2001, y tiene su origen en los resultados mostrados por la Encuesta para la Mejora de las Condiciones de Vida y Trabajo, realizada por la Fundación Europea, que dio cuenta, entre otros, de los siguientes aspectos: la magnitud de manifestaciones de acoso laboral, las causas que pueden dar lugar a riesgos para la salud y que tiene como base la existencia de tensión, un grado de competitividad, menor estabilidad en el empleo y una situación laboral precaria. Ante ello, la Resolución destacó algunos puntos a considerar por los Estados miembros para la efectividad de las medidas antiacoso:

- Prestar mayor atención, reforzar las acciones destinadas a combatirlo e idear nuevas formas para hacerle frente.

- Hacer hincapié en los efectos en la salud física y psíquica. ${ }^{22}$

- Favorecer acciones comunitarias, porque pueden tener efectos normativos e influir en las actitudes, y que por razones de equidad, dichas directrices resultan convenientes.

21 Independientemente de la existencia de otros documentos normativos que en materia de seguridad e higiene prevén medidas de protección de la salud laboral e integral de los trabajadores, como la Directiva 89/391/CEE, del 12 de junio de 1989, la cual marcó el inicio de la aplicación de medidas para promover la mejora de la seguridad y salud de los trabajadores en todos los países de la Unión Europea. Asimismo, la Directiva determinó principios generales para la prevención de los riesgos laborales, así como la eliminación de factores de riesgo y accidentes, información, consulta, formación de los trabajadores, y fijó líneas generales para la aplicación de dichos principios. Igualmente, la Carta Social Europea, del 3 de mayo de 1996, incluía el acoso moral entre los actos condenables o explícitamente hostiles dirigidos de modo repetido contra todo asalariado en el lugar de trabajo.

22 También la Resolución reconoce consecuencias negativas para los empleadores en materia de rentabilidad y eficacia económica de la empresa, a causa del ausentismo derivado de las incapacidades otorgadas a los trabajadores. 
- Unificar criterios y elaborar una definición uniforme para dar una cobertura global en el campo del acoso laboral, previa revisión de las legislaciones nacionales.

- Recomendar a los poderes públicos e interlocutores sociales, algunas políticas de prevención, asistencia a la víctima y erradicación del fenómeno; sistemas de intercambio de experiencias (buenas prácticas), y procedimientos de solución.

- Realizar los estudios para formular una recomendación.

Asimismo, se solicitó a la Comisión Europea adoptar medidas desde la perspectiva de la regulación del caso. Dicha Comisión, en el marco de la Estrategia Comunitaria de Seguridad y Salud en el Trabajo 20022006, consideró diversas formas de acoso psicológico y violencia en el trabajo como riesgo social. ${ }^{23}$

\section{B. Acuerdo Marco Europeo sobre acoso y violencia en el trabajo}

El Acuerdo se suscribió el 27 de abril de 2007 por los interlocutores sociales, previo a las consultas realizadas en el contexto del programa de trabajo de la Comisión Europea, el cual tenía como objetivo prioritario la regulación del acoso laboral en la estrategia comunitaria sobre salud y seguridad en el trabajo para 2002-2006. ${ }^{24}$ El Acuerdo se planteó como metas:

a) Aumentar la sensibilización y entendimiento de los interlocutores sociales sobre el acoso y la violencia en el lugar del trabajo.

b) Proporcionar a los interlocutores sociales de todos los niveles, un marco pragmático para identificar, prevenir y hacer frente a los problemas de acoso y violencia en el trabajo.

23 Comisión de las Comunidades Europeas, Cómo adaptarse a los cambios en la sociedady en el mundo del trabajo: una nueva estrategia comunitaria de seguridad y salud 2002-2006, Bruselas, 11 de marzo de 2002, GOM (2002) 118 final.

24 Comisión de las Comunidades Europeas, "Comunicación de la Comisión al Consejo y al Parlamento Europeo por la que se transmite el Acuerdo Marco Europeo sobre el acoso y la violencia en el trabajo", Bruselas, 8 de noviembre de 2007, COM(2007) 686 final. 
Con base en estos objetivos, las empresas debían redactar una declaración de tolerancia cero hacia el acoso y violencia en el trabajo, así como especificar los procedimientos a seguir en casos de incidentes. ${ }^{25}$

La gran mayoría de los países de la Unión Europea han implementado el Acuerdo, principalmente por tres vías: ${ }^{26}$

a) Por medio de la suscripción de acuerdos nacionales, regionales o sectoriales entre los representantes de empleadores y trabajadores, guías, declaraciones, así como toda una serie de medidas complementarias.

b) Con cambios normativos en materia de seguridad e higiene.

c) Con la creación de una normatividad específica.

\section{Directrices multisectoriales para solucionar la violencia y el acoso de terceros relacionados con el trabajo}

Las directrices fueron suscritas por los interlocutores sociales el 16 de julio de 2010. En ellas se establecen medidas prácticas para adoptarse por los empleadores, los trabajadores, sus representantes y los sindicatos a fin de reducir, prevenir y mitigar la violencia de terceros y sus consecuencias, bajo los siguientes elementos: enfoques de asociación, definiciones claras, prevención a través de la evaluación de riesgos, sensibilización, formación, notificación, seguimiento y una evaluación adecuada. Para lo anterior, los empleadores, previa consulta con los trabajadores, deben desarrollar políticas de acuerdo con la legislación nacional, los convenios colectivos y la

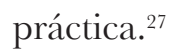

\section{Legislaciones nacionales}

En la Unión Europea se ha reconocido la importancia del acoso laboral como un problema que afecta la seguridad y salud de los trabajadores.

25 Tomar medidas disciplinarias o despido contra los autores de acoso laboral, así como dar asistencia a la víctima y/o reintegrarla.

26 García Viña, Jordi, La incidencia del Acuerdo Marco Europeo sobre acoso y violencia en el trabajo, disponible en: islssl.org/wp-content/uploads/2013/03/spain-Lainciendia-vina.pdf.

27 COESS et al., Directrices multisectoriales para solucionar la violencia y el acoso de terceros relacionado con el trabajo, 2010. 
Algunos Estados miembros cuentan con una normatividad específica para luchar contra el fenómeno; en cambio, otros lo regulan en diversas disposiciones: leyes laborales, códigos penales, de seguridad y salud en el trabajo, etcétera.

\section{A. Legislación especifica}

Cuatro países tienen una ley específica para el acoso laboral; sin embargo, tres son de carácter nacional y una de carácter regional.

\section{a. Suecia}

Este país fue el primero en introducir el acoso laboral (1993), a través de la Ley Básica de Prevención de Riesgos, de alcance nacional. La ley apunta a la prevención, establece medidas tendentes a la recuperación de las víctimas, e imputa al empleador la constatación de un mal ambiente laboral y la expulsión del acosador. ${ }^{28}$

\section{b. Bélgica}

El país regula el caso a través de la Ley sobre Prevención de la Violencia Psicológica en los Lugares de Trabajo, del 10 de enero de 2007, y del Decreto Real del 17 de mayo de 2007. Ambos instrumentos jurídicos tienen alcance nacional. ${ }^{29}$ La Ley hace énfasis en la prevención, y crea la figura de un mediador a fin de ayudar a dirimir los conflictos derivados de la recepción de una denuncia de acoso laboral; igualmente, otorga un plazo de estabilidad de un año en beneficio del denunciante, con el objeto de protegerlo contra eventuales represalias. La Ley prevé como conducta tipificante del acoso laboral a las conductas violentas "externas a la empresa" 30 (postura resistida por la doctrina).

28 La Ley consagra dos principios generales del trabajo: a) la planificación y organización del trabajo para prevenir cualquier riesgo de persecución psicológica en él, y b) manifestación inequívoca del empleador con respecto a situaciones de acoso.

29 Estas leyes sustituyeron a la Ley relativa a la protección contra la violencia y el acoso moral o sexual en el trabajo, del 12 de junio de 2002.

30 Ministerio del Trabajo y Asuntos Sociales, "Nueva reglamentación sobre violencia, el acoso y la carga psicosocial en el trabajo", Revista Actualidad Internacional Sociolaboral, núm. 107, 2007, pp. 103-106. 


\section{c. Reino Unido}

Con base en la Protection from Harassment Act de 1997 y la Dignity at Work Act de 2001, este país regula en forma amplia el fenómeno. Las leyes prevén sanciones y responsabilidad civil a quienes incurran en conductas de asedio injustificadas; a su vez, habilitan el despido mediante un proceso sumario. Además, se considera un delito y se castiga con seis meses de prisión y/o una multa limitada al nivel cinco de la escala.

\section{d. Italia}

El hecho es regulado con algunas leyes de carácter regional; no obstante, la Ley del Lazio, del 11 de julio de 2002, ${ }^{31}$ la cual pretendía aplicarse tanto en beneficio de trabajadores públicos como privados, así como crear centros de atención a cargo de organizaciones sin fines de lucro y el gobierno regional, fue declarada inconstitucional el 19 de diciembre de 2003. ${ }^{32}$

\section{B. Inclusión en ordenamientos y figuras jurídicas diversos}

En Francia se regula el acoso laboral tanto en la vía laboral como en la penal. La Ley 2002/73 de Modernización Social, del 17 de enero de 2002, modificó el Código de Trabajo para introducir la figura en los artículos L-122-49 al 122-53. La Ley ofrece una regulación exhaustiva, pues considera las tres modalidades: descendente, ascendente y horizontal. A su vez, este ordenamiento distingue claramente el acoso moral del sexual con base en los principios de no discriminación e igualdad; también obliga a su inclusión en los convenios colectivos con las respectivas sanciones disciplinarias, y además postula la conciliación como mecanismo de solución de los conflictos, y en caso de no resultar, prevé la intervención de un mediador con potestades decisorias y coercitivas. En materia penal, el caso fue incorporado al libro II, título VII, intitulado "De las torturas y otros delitos contra la integridad moral", en donde se tipifica como un de-

\footnotetext{
31 Bollettino Ufficale della Regione Lazio, Roma, 30 de julio de 2002, supplemento ordinario n. 3.

32 Sentencia N. 359/2003, 10-19 de diciembre de 2003, disponible en: wrwrecortecostituzionale.it/actionSchedaPronuncia.do? anno $=2003$ ङ̊numero $=359$.
} 
lito contra atentados a la persona humana, sancionado con multas y penas privativas de libertad. ${ }^{33}$

En el caso de España, mediante la LO 5/2010, del 23 de junio, fue reformado el código penal para incorporar el acoso laboral al libro II, título VII, intitulado "De las torturas y otros delitos contra la integridad moral". El artículo 173 tipifica como delito el acoso laboral descendente: "A quien dentro de una relación laboral o funcionarial prevaliéndose de superioridad realice contra otros actos hostiles o humillantes, de forma reiterada que supongan «grave acoso»". El castigo va de seis meses a dos años de prisión.

Diversos países regulan el caso mediante el código laboral: Luxemburgo, artículos L 162-12; Suiza, artículos 321 y 328, y Portugal, artículo 24. Por su parte, Dinamarca lo contempla en la Ley de Medio Ambiente Laboral; Holanda, en el Decreto de Condiciones de Trabajo, y Finlandia, en la Ley sobre Seguridad y Salud en el Trabajo. ${ }^{34}$

Por otro lado, Alemania regula el hecho mediante convenios colectivos. Este enfoque cuenta con el respaldo de la Federación Sindical Nacional, la cual se ha encargado de publicar un texto modelo, con la idea de poner énfasis en la "prevención", independientemente de que se consideran comportamientos, procedimientos, sanciones, etcétera. ${ }^{35}$

De acuerdo con lo expuesto, puede apreciarse que la normatividad europea no regula de manera homogénea la figura del acoso laboral, aunque pueden distinguirse, por lo menos, tres tipos de comportamientos, ya sea por separado o combinados: acoso psicológico, discriminación y violencia física. Algunos países se centran en la prevención, mientras que otros van más allá al considerarlo delito, sancionándolo con pena privativa de libertad.

\section{AMÉRICA LATINA}

En América Latina se identifica poco desarrollo de la temática; sin embargo, pueden observarse diferentes soluciones en el tratamiento del acoso laboral.

33 Mella Méndez, L., "El acoso moral profesional en Francia: análisis crítico de sus rasgos configuradores", Revista de Derecho Social, núm. 53, 2011.

34 García Viña, Jordi, op. cit.

35 Graham, Ian, "Para acabar con el hostigamiento ¿es mejor legislar o negociar?", La violencia en el trabajo, OIT, Educación Obrera, 2004, pp. 62, 65 y 66. 
Esta revista forma parte del acervo de la Biblioteca Jurídica Virtual del Instituto de Investigaciones Jurídicas de la UNAM

$\mathrm{Al}$ igual que en los países europeos, en la región existen pocos países que cuentan con una legislación específica; algunos han modificado sus códigos del trabajo, y otros, en cambio, aplican disposiciones previstas en diversos ordenamientos jurídicos: constitucionales y legales.

\section{Legislación específica}

En la región, solamente tres países cuentan con una legislación específica, aunque uno con carácter nacional y los otros dos con carácter regional: Colombia, Argentina y Brasil.

\section{A. Colombia}

Es el único país en América Latina en tener una ley de alcance nacional: la Ley 1010, del 23 de enero de 2006. Dicha Ley intenta prevenir, corregir y sancionar el acoso laboral en el marco de las relaciones de trabajo. ${ }^{36}$ La Ley consta de diecinueve artículos, y tiene como características a las siguientes: ${ }^{37}$

1) Definición. Establece las modalidades en las que se puede dar el acoso: maltrato, persecución, discriminación, inequidad y desprotección. ${ }^{38}$

2) Sujetos. Precisa a los activos, los pasivos y los partícipes.

3) Modalidades. Comprende el descendente, el ascendente y el horizontal.

4) Conductas. Actos de agresión física, comunicación verbal o escrita con contenidos lujuriosos, etcétera.

36 Dicha Ley supera las protecciones especiales sobre la materia reguladas en el Código de Trabajo: artículo 57, núms. 5, 6 y 9, y artículo 59, núm. 9.

37 Sin embargo, es criticada porque presenta varios problemas, tales como la falta de una definición clara que evite las denuncias temerarias, la falta de un órgano especializado en su protección, la falta de sanciones ejemplarizantes en caso de que se ejecute la conducta, y la ausencia de una perspectiva de género en su regulación. Cffr. Garzón, T., Críticas y perspectivas de la Ley 1010 de 2006: una aproximación desde la definición jurídica y psicológica del acoso laboral, 2011.

38 Artículo $7 \mathrm{o}$. 
5) Excepciones. Guestiones de orden disciplinario, exigencias de fidelidad o lealtad, mejoramiento de la eficiencia laboral, evaluación de subalternos, cumplimiento de deberes, etcétera. ${ }^{39}$

6) Mecanismos de prevención. ${ }^{40}$ Prevé la creación de comités e intervención de un inspector de trabajo, actividades de mejoramiento de las relaciones e, incluso, la intervención de una institución de conciliación autorizada legalmente a fin de que amigablemente se supere la situación de acoso laboral. ${ }^{41}$

7) Sanciones. Señala una multa entre dos y diez salarios mínimos mensuales para el acosador y para el empleador tolerante de la situación; así como la obligación de pagar a las empresas prestadoras de salud y las aseguradoras de riesgos profesionales el 50\% del costo del tratamiento de enfermedades profesionales, alteraciones de salud y demás secuelas originadas por el acoso laboral. ${ }^{42}$

8) Procedimiento. Se realiza ante los jueces del trabajo en una audiencia dentro de los treinta días siguientes a la presentación de la solicitud o queja. Previamente, se procede la notificación personal al acosador y al empleador que lo haya tolerado, dentro de los cinco días siguientes al recibo de la solicitud o queja. Las pruebas se ofrecen antes de la audiencia o dentro de ella. La resolución se determinará al finalizar la audiencia, a la cual podrán asistir las partes y los testigos o peritos.

9) Apelación. Ésta procede contra la resolución del caso, y se decidirá en los treinta días siguientes a su interposición. ${ }^{43}$

10) Caducidad de la acción. Ésta opera seis meses después de la fecha en que hayan ocurrido las conductas referidas por la ley. ${ }^{44}$

\section{B. Argentina}

Este país ha regulado el fenómeno a partir de 2002 bajo la denominación de "violencia laboral". Existen ocho leyes de carácter provincial y

\footnotetext{
39 Artículo 8o.

40 Comité de Convivencia Laboral, Aspectos procesales de la Ley de Acoso Laboral, Colombia, Universidad Católica de Colombia, 2008, disponible en: http://portalweb.ucatolica.edu.co.

41 Artículo 9o.

42 Artículo 10.

43 Artículo 13.

44 Artículo 18.
} 
municipal, aunque en siete de ellas el ámbito de aplicación se circunscribe al sector público, y sólo una también comprende al sector privado. Entre la primeras se encuentran las siguientes: Ley 7.232 de 2002, de la Provincia de Tucumán; Ley 5.349 de 2003, de la Provincia de Jujuy; Ley 13.168 Contra la Violencia Laboral de 2004, de la Provincia de Buenos Aires; Ley 1.225 de 2005, de la Ciudad Autónoma de Buenos Aires; Ley 12.434 de 2005, de la Provincia de Santa Fe, y Ley 4.148, de la Provincia de Misiones. Por su parte, la Ley 9.671 de 2006, de la Provincia Entre Ríos, abarca tanto al sector público como al privado.

\section{Brasil}

Desde 2000 este país ha expedido diversas legislaciones estatales y en la administración municipal dirigidas al sector público bajo el término "asedio moral":

a) Leyes estatales: la Ley Complementaria 12.561 de 2006, de Río Grande de Sul; la Ley 3.921 de 2000, de Río de Janeiro; la Ley Complementaria 63, de Par, y la Ley 12.250 contra el Asedio Moral de 2006, del estado de São Paulo.

b) Leyes municipales: Ley 1.163/2000, de Iracemápolis, São Paulo; Ley 2.120/2000, de Ubatuba, São Paulo; Ley 3.243/2001, de Cascavel, Paraná; Ley 358/2001, de Guarulhos, São Paulo; Ley 1.078/2001, de Sidrolandia; Ley 2.982/2001, de Jaboticaba; Ley 13.288/2002, de São Paulo; Ley 189/2002, de Natal; Ley 3.671/2002, de Americana; Ley 11.409/2002, de Campinas; Ley 511 /2003, de São Gabriel do Oeste; Ley 9.736/2003, de Ribeirão Preto; Ley 2.377/2003, de Presidente Venceslau; Ley complementaria 498/2003, de Porto Alegre; Ley 8.629/2004, de Santo Andrés, y Ley 4.205/2006, de Catanduva. ${ }^{45}$ Además, está en discusión el proyecto de Ley 7.202/2010 para considerar el acoso moral como accidente de trabajo.

De acuerdo con las leyes específicas regionales de Argentina y Brasil, aunque en su mayoría presentan un contenido muy reducido y general, pueden desprenderse los siguientes elementos: ${ }^{46}$

45 Nascimento, Sonia Mascaro, Asedio moral, São Paulo, Saraiva, 2009, pp. 6 y 7.

46 Que en cierta forma atienden al repertorio de recomendaciones prácticas de la OIT sobre la violencia en el trabajo. 
- Tienen como objeto prevenir, controlar, sancionar y erradicar el fenómeno.

- Predomina la regulación en el ámbito de la administración pública.

- Definen el fenómeno, así como otros comportamientos, y enlistan algunas formas que dan lugar a estos últimos. ${ }^{47}$

- Prevalece la modalidad ascendente.

- Establecen obligaciones generales tanto para la autoridad que aplicará la ley como para el empleador.

- Enuncian únicamente un procedimiento interno.

- Especifican sanciones consistentes en multas o suspensiones.

Estas leyes constituyen un avance para normar el "acoso laboral", pero aún resultan ser insuficientes por la generalidad en que se aborda el fenómeno, además de dejar fuera de regulación aspectos presentes en el campo de las relaciones laborales.

\section{Reformas a los códigos del trabajo}

En este rubro pueden citarse tres casos recientes. Uno de ellos consiste en que una ley ad hoc contiene normas de reforma de varias legislaciones no específicas, y que, por tanto, sus disposiciones están destinadas a convertirse en artículos de códigos diversos, como el caso de Chile. Los otros dos implican reformas directas al código laboral, que es el supuesto de México y Venezuela. Lo característico de estas legislaciones es la regulación de la figura del acoso laboral como materia distinta del acoso sexual o de la discriminación.

En cuanto a Chile, se expidió la Ley 20.607 el 8 de agosto de 2012, mediante la cual se incorporó como figura jurídica al acoso laboral, y se

47 Por ejemplo, en las diversas leyes argentinas definen el fenómeno como "Toda acción u omisión que atenta contra la dignidad, integridad física, sexual, psicológica y/o social del trabajador ejercida en el ámbito laboral por el empleador, por personal jerárquico o un tercer vinculado directamente con él...”. Y en un artículo diferente se señalan las formas en que se manifiesta: maltrato físico, maltrato psíquico, acoso, acoso sexual, discriminación remunerativa, y toda forma de coacción utilizada por las autoridades, el personal jerárquico y/o los terceros vinculados directamente con ellas. También las leyes brasileñas proporcionan una definición y las diversas formas en las que se manifiesta el evento. 
introdujeron modificaciones en diversos artículos del Código del Trabajo (2o., 160 y 171) y en reglamentaciones administrativas (modificó el artículo 84 de la Ley 18.834 sobre Estatuto Administrativo, y el artículo 82 de la Ley 18.883 del Estatuto Administrativo para Funcionarios Municipales).

Uno de los aspectos relevantes de la ley es la definición de acoso laboral como

Toda conducta que constituya agresión u hostigamiento reiterados, ejercida por el empleador o por uno o más trabajadores, en contra de otro u otros trabajadores, por cualquier medio, y que tenga como resultado para el o los afectados su menoscabo, maltrato o humillación, o bien, que amenace o perjudique su situación laboral o sus oportunidades en el empleo. ${ }^{48}$

También se incluyó a la figura como causal de despido indirecto o rescisión imputable al empleador; ${ }^{49}$ el pago de indemnización, así como el pago de la antigüedad aumentada hasta un $80 \%$; el despido sin derecho a indemnización contra quien cometa el acoso laboral, e incluso se regula el falso reclamo.

Con respecto a México, en el contexto de la reforma a la Ley Federal del Trabajo del 30 de noviembre de 2012, el país introdujo, de alguna forma, el acoso laboral bajo la denominación de "hostigamiento", regulándolo por primera vez y distinguiéndolo del acoso sexual; sin embargo, la definición es bastante limitada: "Ejercicio del poder en una relación de subordinación real de la víctima frente al agresor en el ámbito laboral, que se expresa en conductas verbales, físicas o ambas". Igualmente, se regula a la figura como parte de una de las causales de rescisión de la relación del trabajo imputable tanto al trabajador como al patrón,,$^{50}$ aunque sólo respecto del acoso vertical descendente; también se establecen sanciones. De acuerdo con la doctora Mendizábal, la ley limita el caso a una sola de sus manifestaciones: la descendente, y omite las conductas agresivas de otros sujetos. Faltan disposiciones para responsabilizar al patrón del medio ambiente laboral, así como medidas preventivas, y su consideración como riesgo de trabajo, porque puede desencadenar accidentes y

48 Artículo 2o., inciso 2, del Código del Trabajo, y artículo 1o., núm. 1, de la Ley 20.607 .

49 Artículo 160 del Código del Trabajo.

50 Artículos 3 bis, 47, 51 y 133.

D. R. (C) 2016. UNAM, Instituto de Investigaciones Jurídicas, Boletín Mexicano de Derecho Comparado, núm. 147, pp. 71-98 
enfermedades (cuadros de estrés, ansiedad, problemas digestivos, cambios bruscos de personalidad). ${ }^{51}$

Por su parte, en Venezuela se expidió la Ley Orgánica del Trabajo, de los Trabajadores y Trabajadoras, publicada el 7 de mayo de 2012, ${ }^{52}$ la cual definió al acoso laboral como

...el hostigamiento o conducta abusiva ejercida en forma recurrente o continuada por el patrono o la patrona o sus representantes, o un trabajador o una trabajadora, o un grupo de trabajadores o trabajadoras que atente contra la dignidad o la integridad biopsicosocial de un trabajador, una trabajadora o un grupo de trabajadores y trabajadoras, perturbando el ejercicio de sus labores y poniendo en peligro su trabajo o degradando las condiciones de ambiente laboral.

Además, se reguló a la figura como causa justificada de retiro con derecho a indemnización para el acosado y despido al acosador. De igual forma, el artículo 164 destacó las acciones contra el acoso por parte del Estado, organizaciones sindicales y patrones.

Cabe señalar que Venezuela previamente había regulado, en cierta forma, el tema en la Ley Orgánica de Prevención, Condiciones y Medio Ambiente de Trabajo de 2005, al disponer en su artículo 56, punto 5, como obligación de los patrones: "El abstenerse de realizar, por sí o por sus representantes, toda conducta ofensiva, maliciosa, intimidatoria y de cualquier acto que perjudique psicológica o moralmente a los trabajadores y trabajadoras".

De acuerdo a lo expuesto, puede señalarse que las reformas a los códigos laborales en estos países también constituyen un avance, aunque mínimo, porque tampoco abarcan todas las problemáticas ni establecen los procedimientos ad hoc requeridos, pues sus disposiciones se encuentran ligadas al despido por parte del acosador.

\section{Inclusión en otros ordenamientos y figuras jurídicas}

El resto de los países que hasta el momento carecen de una legislación específica sobre el acoso laboral, o no han reformado sus códigos de

51 Mendizábal Bermúdez, Gabriela, "Acoso laboral", Boletín ADAPT, vol. 1, núm. 1, 2013.

52 Gaceta Oficial, núm. 6.076 extraordinario, 7 de mayo de 2012. 
trabajo para incorporar dicha figura, basan la protección del trabajador en normas de carácter general tanto constitucionales como en las disposiciones de los códigos de trabajo, penales, reglamentos administrativos, código civil, etcétera, en tanto prosperan en sus respectivos proyectos legislativos para regular el caso:

a) Constitución. Se apoyan en esta norma suprema como base de la protección de derechos fundamentales de la persona (dignidad, igualdad ante la ley y la no discriminación, integralidad personal, derecho al trabajo, derecho a la salud, etcétera).

b) Códigos de trabajo. En su mayoría recurren a este instrumento jurídico, pues consideran que aun cuando no regula en forma expresa el hecho, la normativa resulta suficiente para prevenirlo y sancionarlo, en razón de que de su contenido se desprenden las obligaciones y los derechos tanto del empleador como del trabajador, así como las reglas del juego de la relación del trabajo y las consecuencias que conlleva su desacato. Asimismo, se aduce que los principios generales del derecho del trabajo deben ser respetados y cumplidos a cabalidad por las partes, además de que el trato digno del empleador para con el trabajador, y viceversa, o entre los mismos trabajadores, es una obligación inherente e indiscutible en toda relación laboral.

c) Empleo de otras ramas del derecho. Se recurre a tipificaciones que tienen un tratamiento específico e independiente, tales como la coacción, las amenazas, la violencia, etcétera.

Entre los países que se encuentran en este supuesto tenemos a los siguientes:

1) Bolivia y Ecuador. Estos países tienen una base constitucional. En Bolivia, la Constitución, en su artículo 49, establece lo siguiente: “...El Estado protegerá la estabilidad laboral, prohibiéndose el despido injustificado y toda forma de acoso laboral". En el caso de Ecuador, el título II, capítulo sexto, artículo 66, de la Constitución regula el derecho a la integralidad personal, que incluye la integridad física, psíquica, moral y sexual, y una vida libre de violencia en el ámbito público y privado.

2) Costa Rica. Los trabajadores afectados basan sus demandas para reclamar una indemnización con base en la Constitución (artículos 
5o. y 56), el Código de Trabajo (artículos 19; 69, inciso c; 81, y 83, inciso b), y los reglamentos administrativos (la Ley General de Administración Pública). Las denuncias pueden presentarse ante el Ministerio de Trabajo y Seguridad Social (vía conciliación), o bien directamente ante los tribunales de justicia. ${ }^{53}$ En este país han existido diversos proyectos legislativos para regular el fenómeno; por ejemplo, las leyes 16.088, 17.620, 18.040 y 18.184, siendo el más reciente el Proyecto de Ley 18.136 o Ley Contra el Acoso Laboral en el Sector Público y Privado, que el 29 de julio de 2013 fue dictaminado positivamente por la Comisión Permanente Especial de la Mujer, y turnado al Poder Legislativo para su estudio y posible aprobación.

3) Panamá. Este país expidió la Ley 24 (3 de julio de 2007), ${ }^{54}$ con la cual modificó y adicionó artículos a la Ley 9 de 1994, que establece y regula la carrera administrativa y dicta otras disposiciones. A través de este ordenamiento se incorporó la figura del acoso laboral aplicable a los servidores públicos; asimismo, aborda los tres tipos de modalidades del fenómeno: descendente, ascendente y horizontal.

4) Paraguay. Este país intenta proteger mediante el Código del Trabajo -Ley 213 de 1993 (modificada por la Ley 496 de 1995)-, en su artículo 84, a la causal por actos de violencia.

5) Perú. En esta nación existe un párrafo apartado en la Ley 27815, en el artículo 8, numeral 5, del capítulo III del Código de Ética de la Función Pública, que a la letra dice: "El servidor público está prohibido de: presionar, amenazar y/o acosar. Ejercer presiones, amenazas o acoso sexual contra otros servidores públicos o subordinados que puedan afectar la dignidad de la persona o inducir a la realización de acciones dolosas".

6) Uruguay. Desde 2010 se han presentado diversas iniciativas para regular el acoso laboral. ${ }^{55}$ El más reciente proyecto es de 2013: Ley Contra el Acoso Moral en el Trabajo.

53 Vargas Morúa, Elizarda, "Acoso laboral en Costa Rica”, Revista Nacional de Administración, núm. 2, enero-junio de 2011, p. 75.

54 Publicada en la Gaceta Oficial del 3 de julio de 2007.

55 "Acoso moral en las relaciones de trabajo", presentado el 26 de agosto de 2009, Comisión de Legislación del Trabajo, 2010. 
De acuerdo con lo expuesto, los países que a través de diversas disposiciones legales pretenden la protección contra el acoso laboral no ignoran lo limitado que resultan ser las mismas, y debido a ello, ha sido la jurisprudencia la que termina delimitando las normas jurídicas para configurar y sancionar el hecho.

\section{GONCLUSIONES}

El acoso laboral es objeto de tratamiento, en alguna medida, en los ordenamientos jurídicos. Su incorporación ha sido diferente, y no sólo desde el punto de vista cronológico, sino también por su resultado.

Puede señalarse que la OIT hasta el momento ha seguido un enfoque previsor basado en los sistemas de gestión de la seguridad y salud en el trabajo, con miras a avanzar hacia un enfoque integrado, proactivo y preventivo. Por su parte, la Unión Europea, a través de sus diversos documentos, revela una preocupación y un papel didáctico sobre el fenómeno (con sus guías, directrices, etcétera), independientemente de que la temática ha sido objeto de regulación en las negociaciones colectivas y en los códigos de ética. Sin embargo, ambas instancias internacionales no han aprobado ningún instrumento jurídico vinculante.

Tanto en Europa como en América Latina, algunos países han aprobado legislaciones específicas destinadas a prevenir, sancionar y erradicar los comportamientos del acoso laboral; en cambio, otros han confiado a instrumentos vigentes el combate al caso. La normatividad existente va desde la prevención hasta atribuirle a la figura el carácter delictivo.

Dado el abanico jurídico existente (normas dispersas y distribuidas de manera no necesariamente sistemática, gran cantidad de definiciones heterogéneas y regulación de diversas conductas, entre otros elementos), resulta difícil extraer conclusiones homogéneas del tratamiento que se le está dando al acoso laboral. A pesar de ello, es posible reconocer un avance jurídico, aunque todavía endeble, razón por la cual en muchos países, principalmente de América Latina, la jurisprudencia ha sido determinante para cubrir los vacíos relativos al caso. Asimismo, en la actualidad existen varias iniciativas o proyectos de ley en diversos países de la región para reconocer, definir y regular el suceso.

En este sentido, puede señalarse que el tratamiento jurídico del tema aún no está resuelto, pues falta mucho por hacer en diferentes rubros; por 
ejemplo, la adopción de medidas de prevención específicas, acentuar la protección de la víctima, reafirmar la responsabilidad del empleador, y reconocer el acoso laboral como un riesgo de trabajo, porque se ubica dentro de los denominados "riesgos psicosociales" al convertirse en las últimas décadas en uno de los principales problemas de salud laboral, el cual, además, merece una especial atención, toda vez que el daño producido impide al empleado realizar su trabajo, situación que conlleva su exclusión.

En forma específica, una temática aún ausente en las diversas legislaciones es la perspectiva de género, cuya regulación es esencial para las mujeres, ya que, por un lado, al contar con menores cuotas de poder en el trabajo, ellas son quienes enfrentan mayor desprotección frente a este fenómeno, y por otro lado, porque no sólo son las víctimas más frecuentes, sino que también son acosadas de manera diferente a los varones.

Ante esta ausencia de perspectiva de género, varios países, sobre todo en América Latina, pretenden la regulación del fenómeno a través de las leyes contra la violencia hacia las mujeres ${ }^{56}$ que si bien constituyen un gran avance en la aproximación a la problemática general de violencia que enfrenta este sector, resultan limitadas, porque las sanciones impuestas no se refieren propiamente al caso. En resumen, se necesita una ley específica integral que comprenda los diversos aspectos del fenómeno.

\section{BIBLIOGRAFÍA}

COESS et al., Directrices multisectoriales para solucionar la violencia y el acoso de terceros relacionado con el trabajo, 2010.

Comisión de las Comunidades Europeas, "Comunicación de la Comisión al Consejo y al Parlamento Europeo por la que se transmite el Acuerdo Marco Europeo sobre el acoso y la violencia en el trabajo", Bruselas, 8 de noviembre de 2007, $\operatorname{COM}(2007) 686$ final.

Comisión Europea, Cómo adaptarse a los cambios en la sociedad y en el mundo del trabajo: una nueva estrategia comunitaria de seguridad y salud 2002-2006, Bruselas, 11 de marzo de 2002, COM (2002) 118 final.

56 En este sentido, México expidió la Ley General de Acceso a las Mujeres a una Vida libre de Violencia, que incluye como una modalidad la violencia docente y laboral; Nicaragua, la Ley 779 (Ley Integral Contra la Violencia hacia las Mujeres); El Salvador, la Ley Especial Integral para una Vida Libre de Violencia para las Mujeres, por citar algunos ejemplos. 
Esta revista forma parte del acervo de la Biblioteca Jurídica Virtual del Instituto de Investigaciones Jurídicas de la UNAM

García ViÑA, Jordi, La incidencia del Acuerdo Marco Europeo sobre acoso y violencia en el trabajo, disponible en: islsslorg/wp-content/uploads/2013/03/ spain-Lainciendia-vina.pdf.

GARZÓn, T., Críticas y perspectivas de la Ley 1010 de 2006: una aproximación desde la definición jurídica y psicológica del acoso laboral, 2011.

GRAHAM, Ian, "Para acabar con el hostigamiento ¿es mejor legislar o negociar?", La violencia en el trabajo, OIT, Educación Obrera, 2004.

Hirigoyen, Marie-France, El acoso moral. El maltrato psicológico en la vida cotidiana, Madrid, Paidós, 1999.

-, El acoso moral en el trabajo: distinguir lo verdadero de lo falso, Barcelona, Paidós, 2011.

Leymann, Heinz, Inventory Psychological Terrorization, 1990.

-, Mobbing. La persécution au travail, Seúl-París, 1996.

López Cabarcos, M. Ángeles y VÁzQuez Rodríguez, Paula, El mobbing en las organizaciones. La ausencia de un concepto global y único, 2007.

LORENZ, Konrad, Sobre la agresión: el pretendido mal, México, Siglo Veintiuno, 1985.

MARTínez LEÓN, M. et al., "El acoso psicológico en el trabajo o mobbing: patología emergente", Gaceta Internacional de Ciencias Forenses, núm. 3, abril-junio de 2012.

MelLa MÉNDEZ, L., "El acoso moral profesional en Francia: análisis crítico de sus rasgos configuradores", Revista de Derecho Social, núm. 53, 2011.

MENDIZÁBAL BERMúdEZ, Gabriela, "Acoso laboral", Boletín ADAPT, vol. 1, núm. 1, 2013.

Ministerio Del Trabajo y Asuntos Sociales, "Nueva reglamentación sobre violencia, el acoso y la carga psicosocial en el trabajo", Revista Actualidad Internacional Sociolaboral, núm. 107, 2007.

Nascimento, Sonia Mascaro, Asedio moral, São Paulo, Saraiva, 2009.

Oceguera Ávalos, Angélica et al., "Estudio comparado de la legislación del mobbing en Latinoamérica", Acta Republicana Política y Sociedad, año 8, núm. 8, 2009.

OIT, Lista de enfermedades profesionales de la OIT (revisada en 2010), Ginebra, 2010.

$\longrightarrow$, Repertorio de recomendaciones prácticas sobre la violencia en el lugar de trabajo en el sector de los servicios y medidas para combatirla, Ginebra, Oficina Internacional del Trabajo, 2003.

—. Violencia en el trabajo, Ginebra, 2000. 
Esta revista forma parte del acervo de la Biblioteca Jurídica Virtual del Instituto de Investigaciones Jurídicas de la UNAM

PIÑUel y Zabala, Iñaki, Mobbing: cómo sobrevivir al acoso psicológico en el trabajo, Bilbao, Sal Terrae, 2001.

Plena SAInt, Florencia et al., Cuando el trabajo nos castiga. Debates sobre el mobbing en México, México, ONM-Sedisem-UAM Azcapotzalco, 2007. Servicio público federal de empleo, trabajo y concertación social, Kluwer, 2007.

VARGaS MORÚA, Elizarda, "Acoso laboral en Costa Rica", Revista Nacional de Administración, núm. 2, enero-junio de 2011. 